\title{
Responsabilidade da educação física escolar: concepções dos professores que atuam na formação inicial
}

\author{
Ivan Carlos Bagnara ${ }^{\mathrm{a}, *}{ }^{\oplus}$, Paulo Evaldo Fensterseifer ${ }^{\mathrm{C}}$
}

Palavras-chave:

Educação superior; Formação de professores; Educação física; Política.

\section{Keywords:}

Higher education; Teacher training; Physical education; Politics.

\section{Palavras Chave:}

Educación superior; Formación de profesores; Educación física; Política.

\begin{abstract}
RESUMO
Com o objetivo de identificar e analisar as concepções que os professores que atuam na formação inicial (FI) em educação física (EF) têm acerca da responsabilidade da educação física escolar (EFE), foi feita uma pesquisa qualitativa colaborativa, da qual participaram 12 docentes que atuam na FI em EF. Os resultados indicam haver heterogeneidade na compreensão das responsabilidades da $\mathrm{EFE}$, as quais suscitaram quatro categorias de análise: promoção da saúde, movimento corporal, interação humana e conhecimento da legislação e de teorias. Conclui-se que as concepções dos professores carecem de sustentação teórica, pois se apoiam na mídia e no senso comum (modismos) e desconhecem os marcos legais, os quais podem ser politicamente tensionados, porém não ignorados.
\end{abstract}

\begin{abstract}
In order to identify and analyze teachers' conceptions that work with Initial Formation (IF) in Physical Education (PE) and their responsibility about School Physical Education, a qualitative collaborative research was carried out, in which twelve teachers participated. The results indicate that there is heterogeneity in understanding the responsibilities of School Physical Education (SPE), which gave rise to four categories of analysis: health promotion, body movement, human interaction and knowledge of legislation and theories. In conclusion, that teachers' conceptions need theoretical support, because they rely on common sense (fad), ignoring the legal marks, which can be politically tension but not ignored.
\end{abstract}

\section{RESUMEN}

Con el objetivo de identificar y analizar las concepciones que los profesores que trabajan en la formación inicial (FI) en educación física (EF) poseen acerca de la responsabilidad de esta en la escuela, se llevó a cabo una investigación cualitativa colaborativa, con la participación de doce docentes que trabajan en la FI en EF. Los resultados indican heterogeneidad de comprensión de las responsabilidades de la EF, las cuales están vinculadas con cuatro categorías de análisis: promoción de la salud, movimiento corporal, interacción humana y conocimiento de la legislación y las teorías. Se concluye que las concepciones de los profesores carecen de sustentación teórica, pues se apoyan en los medios de comunicación y en el sentido común, y desconocen los marcos legales, los cuales pueden ser políticamente tensados, pero no ignorados.

\footnotetext{
a Instituto Federal de Educação, Ciência e Tecnologia do Rio Grande do Sul (IFRS), Erechim, RS, Brasil.

b Universidade Regional do Noroeste do Estado do Rio Grande do Sul (Unijuí), Ijuí, RS, Brasil.
}

\author{
*Autor correspondente: \\ Ivan Carlos Bagnara \\ E-mail: ivan.bagnara@vacaria.ifrs.edu.br
}




\section{INTRODUÇÃO}

Qual a responsabilidade da educação física escolar (EFE)? Ao elaborar essa pergunta, indicamos a centralidade do texto, pois entendemos que formular respostas para a pergunta em tela é condição fundamental para perspectivar, no caso da educação física (EF), o desenvolvimento de uma disciplina educativa com legitimidade.

Nos últimos anos, principalmente após a virada cultural ${ }^{1}$, têm sido empreendidos esforços para instituir a EFE sob o prisma de uma disciplina educativa. O fenômeno do abandono docente ou desinvestimento pedagógico parece ter se constituído num entrave para isso (González e Fensterseifer, 2006; Machado et al, 2010; Bracht et al, 2018a). Tal fenômeno é caracterizado por González e Fensterseifer (2006) como o tipo de atuação daqueles profissionais que não apresentam grandes pretensões com sua ação docente, ou mesmo nenhuma, além de ocupar seus alunos com alguma atividade prática.

Em outra dimensão, há publicações (González e Fensterseifer, 2009a; González e Fensterseifer, 2010; González e Fraga, 2012; Bracht et al, 2014; Bracht et al, 2018b) que apresentam perspectivas inovadoras ou sugestões para que se possa avançar na elaboração de estratégias didático-pedagógicas que deem conta da implantação da EFE sob o prisma de uma disciplina educativa. Ao analisar tais publicações, percebe-se que há aspectos que são comuns tanto para os casos de inovação pedagógica quanto de abandono docente. Um deles está relacionado à compreensão que os envolvidos têm acerca da responsabilidade da EF enquanto disciplina escolar e da capacidade de operar com esses conceitos na estruturação da ação docente. Em casos de inovação pedagógica, as evidências teóricas indicam haver clareza, por parte dos professores, sobre a responsabilidade da EFE. Inversamente, em casos de abandono docente, a impressão que se tem é que há dificuldade de elaborar respostas consistentes para essa problemática.

No nosso entendimento, ter clareza acerca da responsabilidade social da escola e da EFE é condição sine qua non para instituir, legitimamente, uma disciplina educativa. Tratamos isso como um problema político, o qual, hipoteticamente e aparentemente, tem sido ignorado ou tratado com superficialidade

\footnotetext{
${ }^{1}$ Entendemos como virada cultural a mudança de perspectiva na compreensão do corpo e do movimento humano, reconhece-se que ambos, para serem compreendidos em toda sua magnitude, necessitam ser reconhecidos como manifestação da cultura e essa, por sua vez, configurada nos diferentes contextos sociohistóricos. Essa inflexão no interior da EF significou a ruptura com a tradição biologista e mecanicista, demandou a concorrência de novos aportes teóricos para compreender aquilo que passou a ser o campo temático da EF, a cultura corporal de movimento.
}

na e pela formação inicial (FI). Com base no descrito, perguntamos: quais são as concepções que os docentes que atuam na Fl em licenciatura em EF têm acerca das responsabilidades da EFE?

Assim como Bracht et al, 2014, compreendemos que a $\mathrm{Fl}$ não tem capacidade para resolver os problemas do egresso e da própria EF "antecipadamente", mas entendemos que poderia e deveria contribuir com uma formação reflexiva e voltada para a tomada de consciência acerca de alguns temas basilares e fundamentais para a intervenção pedagógica escolar. Nessa conjuntura, objetivamos identificar e analisar as concepções que os professores que atuam na FI em nível de licenciatura em EF têm acerca das responsabilidades da EFE, as quais impactam, em maior ou menor medida, a formação dos novos professores de $E F$, sujeitos responsáveis por desenvolver a EFE enquanto disciplina educativa.

\section{METODOLOGIA}

Este trabalho ${ }^{2}$ é resultado de uma pesquisa colaborativa desenvolvida na perspectiva qualitativa, em que os sujeitos participantes foram estimulados a refletir sobre a própria práxis e, com base nessa, debater acerca de suas concepções teóricas e práticas pedagógicas desenvolvidas. A pesquisa colaborativa foi estruturada, conforme orienta Desgagné (2007), com o objetivo de considerar o ponto de vista dos professores sobre a própria prática; interessar-se pelas reflexões em seus contextos de ação; analisar suas maneiras de enfrentar as situações; privilegiar as competências do ator em contexto; não dirigir um olhar normativo e exterior sobre suas ações, mas, por outro lado, procurar, com eles, no interior do contexto, compreender em que se apoiava esse agir.

Do ponto de vista instrumental, nos valemos da ideia de Brandão (2003), em que as perguntas e problemáticas que emergiram foram tratadas a várias mãos, num grupo de discussão. 0 grupo de discussão foi composto por 12 professores, os quais atuavam como docentes no curso de licenciatura em EF de uma instituição de ensino superior (IES) particular, localizada no Norte do Estado do RS. Dos docentes, nove tinham título de mestre (três cursavam doutorado como alunos regulares e dois como alunos especiais) e três de especialista. Dos 12 docentes, sete tinham FI em EF (Ivan³, Maria, Carlos, João, Pedro, Fernando e Ângela); desses, um também cursava pedagogia (Fernando). Uma docente tinha $\mathrm{Fl}$ em pedagogia (Dora), dois em

\footnotetext{
${ }^{2}$ Constitui-se num recorte da tese de doutorado elaborada pelo primeiro autor, sob orientação do segundo. Ainda, o primeiro autor fez parte do grupo de professores participantes da pesquisa.

${ }^{3}$ Nome verdadeiro. Os demais são fictícios.
} 
fisioterapia (Manuela e Mateus), um em enfermagem (André) e uma em letras (Andreia).

A pesquisa consistiu em debater, no âmbito da $\mathrm{Fl}$, como são enfrentados os desafios políticos, curriculares e didáticos da EFE. A pesquisa ocorreu em seis encontros e teve duração de nove meses. Constituem o corpus deste texto os dados produzidos no debate acerca dos aspectos políticos da EFE.

Os dados foram produzidos por meio de anotações em Diário de Campo (DC) e elaboração de narrativas docentes. Todos os encontros do grupo foram gravados em áudio. No fim, o áudio era ouvido na íntegra e o DC, quando necessário, passava por ajustes. Além do DC, solicitamos a elaboração de narrativas docentes. A produção de narrativas, de acordo com Molina et al, 2010, permite ao participante a experiência da reflexão, da constante "autointerrogação", e possibilita ressignificar o vivido.

Os dados foram examinados com o método de análise de conteúdo proposto por Bardin (2011). A direção da IES assinou o Termo de Autorização de Participação Institucional e os participantes assinaram o Termo de Consentimento Livre e Esclarecido. A pesquisa foi submetida ao Comitê de Ética e aprovada sob o Parecer Consubstanciado número 1.148.600. O estudo seguiu as normas para pesquisa que envolvem seres humanos e a participação, tanto dos sujeitos como da instituição, ocorreu de forma voluntária.

\section{Responsabilidade da educação física escolar: os professores são formados para quê?}

Primeiramente, destacamos nossa compreensão acerca da responsabilidade da EFE. Assim, a EFE tem a responsabilidade de, ao longo dos anos escolares, permitir aos estudantes conhecer, vivenciar e problematizar os conhecimentos relacionados às práticas corporais sistematizadas, potencializa a emancipação intelectual e a formação de sujeitos políticos e favorece, à medida que desnaturaliza os assuntos tratados, a tomada de decisões autônomas. Para isso, as práticas corporais, entendidas como manifestações das possibilidades expressivas dos sujeitos e patrimônio cultural da humanidade, devem ser tratadas de forma pluridimensional, fornecer aos estudantes os conhecimentos necessários para participar, de forma autoral, da tomada de decisões na sociedade em que vivem.

No que concerne aos dados produzidos pelo estudo, no início do debate o professor Pedro afirmou: "Não vejo a EF na escola com outra função que não seja a promoção da saúde. Nossa responsabilidade enquanto professor de EF é muito grande, principalmente no quesito saúde".
Outros professores manifestaram opiniões nessa linha:

"A EFE deve integrar os estudantes na cultura corporal de movimento, despertando o gosto pela atividade física, fazendo com que sejam capazes de conhecer e compreender a sua importância para a saúde e a qualidade de vida. Os estudantes precisam ter a visão crítica, social sobre a questão da saúde e qualidade de vida. Eles precisam entender em como ter mecanismos para melhorá-las" (Professor Carlos).

"A longevidade já é uma marca no Brasil e é preciso envelhecer com saúde para se ter qualidade de vida; assim sendo, é muito mais fácil e efetivo criar o hábito de praticar atividades físicas desde cedo. Se olharmos para os países desenvolvidos que investem em educação como prioridade, podemos observar que há estímulo para o cuidado com o corpo e incentivo à prática esportiva, isso porque já se reconhece o benefício da atividade física, do exercício físico, tanto para o desenvolvimento físico quanto mental" (Professora Manuela).

"Quando as crianças tiverem o hábito de praticar atividades físicas desde pequenas, levarão com elas esse legado, e já estaremos trabalhando a prevenção de várias doenças" (Professor André).

Aideia da EFE relacionada quase que exclusivamente com a saúde e a qualidade de vida é uma concepção muito presente no cotidiano escolar e, nesse caso, também no cotidiano formador. Essa visão, mesmo que pertinente, necessita ser mediada e mais bem compreendida. Refletir acerca dessa possibilidade permite pensar no potencial de sentido implícito nesse discurso; afinal, o debate sobre saúde e qualidade de vida pode ser considerado o ponto central da EFE ou seria mais um aspecto de problematização?

Entendemos que parece apropriado inserir o debate sobre a saúde na EFE na forma de conteúdos escolares, sem perder de vista que a maneira de problematização também é uma variável importante. Assim, é preciso centrar o debate da EFE nas práticas corporais, tratá-las como produções culturais da humanidade vinculadas ao lazer e cuidado com o corpo e a saúde, e não ao contrário, em que o debate sobre a saúde se constitua na centralidade e esteja vinculado exclusivamente às práticas corporais. Essa problematização deve oferecer condições para que os estudantes compreendam os elementos que interferem na relação das práticas corporais com a saúde e qualidade de vida, todavia sem reduzir ou limitar a compreensão dos conceitos envolvidos.

\footnotetext{
${ }^{4}$ Perspectiva legitimadora que parece ganhar força diante de fenômenos como, por exemplo, o sedentarismo e a obesidade infantil.
} 
De certa forma, a concepção de que a EFE tem como papel principal a promoção da saúde e a qualidade de vida tem um forte apelo ao senso comum. Dados interessantes são descritos por Silva et al, 2009, ao afirmar que quando os acadêmicos iniciam a Fl em EF, acreditam que a EF lida com o corpo na perspectiva de promoção de saúde e qualidade de vida. Em contrapartida, ao longo dos anos de formação, depende de como esse processo formativo foi conduzido e em quais pressupostos teóricos se sustentou, haveria possibilidades de vislumbrar, pelo menos inicialmente, um contexto diferente. Os dados evidenciaram que na fase final do curso os acadêmicos demonstraram maior preocupação com os aspectos pedagógicos; entretanto, ainda permanecem hegemônicas as concepções de que a EF tem como premissa central a aprendizagem motora, a aptidão física e a promoção e manutenção da saúde.

Com base no descrito, é possível pressupor que a forma como os egressos desenvolverão a EF na escola depende, também, de como a FI potencializou a compreensão acerca das responsabilidades da EFE. Com essa perspectiva como pano de fundo, citamos um recorte da fala do professor Fernando, para o qual "a formação deve focar na tomada de consciência por parte do acadêmico sobre as várias temáticas que permeiam o campo da EF", perspectiva que aponta para a necessidade de uma FI pautada pela reflexividade, e não pela "aplicabilidade" do conhecimento.

Para a professora Maria, a EFE "é uma área com diversos desdobramentos". Assim, no currículo escolar, entende como essencial "o desenvolvimento da cultura corporal de movimento. E com base nisso, reconhecer o movimento como elemento da cultura e da sociedade, procurando contribuir para a formação integral do estudante como cidadão consciente e crítico". Nesse caso, percebe-se que as preocupações da EFE estariam para além da saúde da população, para além do aspecto biológico do ser humano. Pensando na perspectiva do movimento humano, o professor João entende que "a EF tem, além das questões cognitivas e socioafetivas, a responsabilidade com suas raízes, que é o movimento corporal. É preciso estimular o estudante a refletir e entender as questões corporais da EF".

De fato, a EFE tem, em sua intervenção pedagógica, a particularidade do movimento corporal. Um possível problema com relação a isso, porém, é que, ao longo de sua história a EFE tem-se pautado somente nos elementos corporais e se preocupado pouco com as questões relacionadas ao "saber" sobre o movimento corporal. Viver de fato o movimento pode abrir portas, entre outras coisas, para uma perspectiva estética da
$E F$, algo que parece distante da escola e do próprio campo, muito em conta pelo problema de a EFE ter sido tomada como espaço de vivências de práticas corporais com objetivos vinculados a essas, distante, portanto, dos objetivos da instituição escolar e, assim, privando o indivíduo de uma experiência sensível acerca do movimento corporal. Nesse sentido, para abarcar os avanços teóricos da área, o fazer e o praticar na EFE não são mais suficientes.

Um aspecto que parece ser importante considerar se refere ao fato de que necessitamos ficar atentos ao "possível reducionismo na compreensão dos espaços institucionais, buscando com isso potencializar outras significações" (Fensterseifer, 2013, p. 48). Assim, acreditar que a EFE necessita dar conta da saúde, da interação humana ou das práticas corporais pode não ser um problema. A questão aqui parece estar mais relacionada "com que base" e "de que maneira" esses conteúdos são tratados. Dessa forma, o que pode se constituir como um problema é entender que a EFE deva responder por somente uma dessas perspectivas, ignorando as outras, e, o que poderia ser ainda pior, desconectada do projeto da escola e descolada do contexto social. É preciso ter claro que a forma de tratamento dada aos conteúdos de especificidade da $\mathrm{EFE}$, se reducionista, pode desperdiçar possivelmente a única chance de tratar esses conteúdos de modo alargado e com profundidade, sem os constrangimentos das demais instituições.

Debater sobre o potencial de interação humana que as aulas de EF podem proporcionar aos estudantes também se constitui como uma categoria de análise. Nesse sentido, o professor Fernando afirma:

"A EF tem uma característica única, ela envolve o movimento, a saída da sala de aula, a interação, a formação em outros espaços, que não os comuns da educação tradicional, e ela pode aproveitar isso para ir além do tradicional. Uma aula de EF pode ser um ótimo momento para potencializar a interação humana e adquirir conhecimentos importantíssimos para os seres humanos, união, colaboração, respeito, integração, amizade, espírito de equipe, diálogo etc."

O professor Fernando aborda elementos relacionados à convivência em grupo. As características das aulas de EF, em grande medida, potencializam a vivência de atividades cooperativas, de respeito, colaboração, entre outros, e em diversos momentos vivenciar essas questões é de extrema relevância para o contexto da sociedade contemporânea. No entanto, não se pode esquecer que a EFE tem os conteúdos e conhecimentos de sua especificidade e "educar o caráter através do corpo", além de ser algo reducionista, poderia não se constituir como uma preocupação 
central dessa disciplina escolar. Em outras palavras: não se trata de ignorar a possibilidade de vivências numa perspectiva relacional, de valores, de interação humana; porém, esses aspectos necessitariam estar vinculados aos objetivos e especificidades maiores da EFE. Ainda, o desenvolvimento de valores considerados positivos depende do modo como as aulas de EF são conduzidas, não há relação linear e automática com essa positividade.

A EF é uma disciplina que tem características peculiares, é uma das suas responsabilidades a de permitir aos alunos o desenvolvimento de suas potencialidades, de forma democrática e não seletiva, com vistas ao seu aprimoramento integral. Além disso, deve contemplar momentos significativos para proporcionar, de forma livre e descontraída, a integração do aluno à escola e à comunidade, uma vez que atividades físicas têm grande potencial para a interação humana (Professora Ângela).

Pensando na perspectiva de interação humana proporcionada pelas particularidades da EFE, podese fazer um contraponto, pois na escola o tempo todo tratamos de interações e relações humanas. Entendemos que a EFE, por desenvolver seu processo formativo, em grande medida, em espaços distintos da sala de aula proporciona uma diversidade de relações e interações humanas, mas nas aulas de outros componentes curriculares, nos intervalos, no caminho para casa, na prática esportiva ou nas brincadeiras com os amigos, seja onde for, também ocorrem interações humanas. Não ignoramos que na EFE diferentes formas de interação humana ocorrem durante as distintas práticas corporais, pois se lida com diferenças de várias ordens e conviver com elas pode potencializar a tomada de consciência acerca do tema, algo fundamental para a qualidade dessa interação. Em contrapartida, entendemos que a tomada de consciência pode ocorrer também nos outros espaços escolares e durante as aulas de todas as disciplinas, e não somente na $\mathrm{EF}$.

O debate promovido até esse ponto converge para a última categoria de análise neste texto: o conhecimento da legislação e de teorias específicas que tratam das responsabilidades da EFE. Referente a isso, a professora Manuela afirma: "Tenho lido algumas coisas sobre o tema, mas confesso que ainda falta muito para aprender". O professor João reconhece que "sempre foi algo distante e desconhecido, e isso me permitiu falhar em diversos aspectos e momentos, por não entender o todo do processo, nem as nossas responsabilidades. Mas reconheço isso hoje, depois que começamos a debater sobre o assunto". As anotações do DC indicam que "grande parte dos integrantes do colegiado do curso não conhece o projeto do próprio curso em que atua". Dessa forma, pode-se suspeitar que os professores (em sua maioria) conhecem de forma mais aprofundada o lugar das disciplinas que ministram, não têm uma visão abrangente do processo formativo. Assim, efetivar uma formação integrada e articulada pode ser considerado "loteria".

O professor André afirma que "não conhecemos o perfil do egresso e esse simples aspecto pode prejudicar a formação". Se não conhece o perfil do egresso, cada professor pode direcionar o processo formativo para a direção que quiser, e isso é um problema, pois possibilita ao egresso assumir a condição de docente sem ter clareza de sua responsabilidade. Reconhecemos o perfil do egresso como um elemento muito importante do processo formativo e o consideramos um "horizonte de formação".

Tratar do perfil do egresso como um "horizonte da formação" remete à ideia de que se intenciona formar um professor com determinado perfil, apesar de não haver garantias da "materialização" desse. Pensar por essa perspectiva possibilita valorizar o processo formativo institucional, pois, de acordo com Rocha e Nascimento, 2017(, p. 57), "uma instituição que desvaloriza suas metas e fins, ou delega a outrem a reflexão daquilo que almeja, abdica de pensar no seu papel e adota postura ventricular, na qual instrumentos e meios podem assumir contornos terminais, neutros, de fácil tendência às ideias feitas e alienadas".

No nosso ponto de vista, há um problema quando cada professor, a seu modo, estabelece uma intencionalidade valorativa para o processo formativo desconectada dos demais. Isso não significa dizer que deveria haver uma ortodoxia, uma homogeneidade, mas a compreensão de que, mesmo que plurais, as perspectivas adotadas pelos professores formadores deveriam ser tensionadas por um "ideal de formação" que permita certa convergência nos propósitos (pactuada e revisada).

Para Fensterseifer (2009), ao configurar um "perfil profissional" orientador do curso de formação, não se podem ignorar as atividades laborais historicamente vinculadas à área, tampouco as emergentes. Toda atuação profissional orienta-se, mesmo que não de forma explícita, por objetivos e finalidades, os quais dão significado ao processo formativo. No âmbito institucional essa questão é o arcabouço legal profissional inegociável.

Analisar a intencionalidade formativa de cada professor na $\mathrm{Fl}$ pode se tornar um ótimo exercício para identificar e compreender as possíveis lacunas deixadas pelo processo formativo. No caso deste texto, para ilustrar a questão, intencionalmente 
selecionamos dois recortes (vinculados ao curso de licenciatura), que podem ser considerados extremos:

"O professor de EF deve gerir programas de exercícios físicos destinados ao indivíduo, seja na escola ou fora dela, indiferente do objetivo (estético, saúde, desempenho) [...] Nossa responsabilidade social passa por um sentido muito abrangente por haver muitas opções de trabalho, mas a questão principal é a ligada à saúde" (Professor Pedro).

"Os professores de EF devem acompanhar todas as discussões que dizem respeito às teorias educacionais. E mais: perceber esses movimentos que dão rumos à educação e à escola, pois, como parte desse todo, o professor de EF também tem que assumir uma postura dentro da escola, e não ser visto apenas como o professor que dá atividades esportivas, mas como um ser responsável pelo presente e pelo futuro dos seres humanos. [...] O professor tem que ter sensibilidade pedagógica e saber o que fazer nas mais diversas situações. Para isso, precisa de um amplo conhecimento acerca das teorias educacionais e uma postura ética, responsável e crítica para saber agir diante dos acontecimentos" (Professor Fernando).

O recorte da narrativa do professor Fernando indica que a formação que procura desenvolver assume um caráter duplo, pois, ao mesmo tempo em que aponta para a imprevisibilidade de uma formação preocupada com o futuro, preocupa-se também com o presente. A afirmação do professor Pedro, em outra dimensão, remete à crítica elaborada por Rocha e Nascimento, 2017, para os quais o professor deve ser formado para além de unicamente dominar técnicas para chegar a algum objetivo, ou dar conta de alguma intencionalidade por meio de habilidades "aplicadas". É preciso romper com a crença de que ao professor basta dominar e aplicar com competência um instrumental técnico e executar mecanicamente tarefas de cunho imediatista.

Parece-nos fundamental estar ciente de que o professor formador direciona a intencionalidade do processo formativo, pois, para Rocha e Nascimento, 2017, o comprometimento do professor pelo seu papel mediador, e sua coparticipação qualitativa no processo de formação dos egressos, tem significativa influência. Ou seja, o professor partilha com os acadêmicos suas concepções e significados, os influencia.

De certa forma, essa miscelânea compreensiva por parte dos professores formadores constitui um problema, pois, para González e Fensterseifer (2009b), por mais que a expressão das crenças pessoais seja feita de forma implícita, como consequência se estabelece, no imaginário acadêmico, a visão de uma disciplina escolar fragmentada e, muitas vezes, contraditória.
Não conduzir o processo formativo pautado por um projeto sólido e vivenciado de modo articulado pode contribuir para a inserção de professores de EF, na escola, que desconhecem suas responsabilidades educativas e desenvolvedores de ações pedagógicas fragmentadas e "espontaneístas".

Outro ponto relacionado a esse debate tem relação com as teorias que embasam as concepções acerca da responsabilidade da EFE na FI. Na visão da professora Maria, "os professores que estão envolvidos com disciplinas de caráter mais pedagógico, filosófico, devem desenvolver leituras ligadas à problematização da EFE enquanto disciplina escolar". Em contrapartida, outros não se preocupam com essa questão, pois a "disciplina é muito específica; não consta na ementa; não tem tempo para tais leituras; não havia se dado conta disso; esse aspecto nunca chamou atenção" (DC).

Os dados produzidos ao longo da pesquisa indicam que os professores "não conhecem a legislação específica e não desenvolvem estudos e leituras acerca da especificidade da EFE" (DC). O professor Pedro reconhece: "Não estou inteirado da legislação educacional". Esse dado chama a atenção para uma situação preocupante, pois de certa forma indica que o processo formativo está "à deriva". O professor Fernando afirma: "Eu até anotei aqui, vou trabalhar sobre a responsabilidade ou função da escola e da EFE em filosofia da educação no próximo semestre. Essa disciplina é o chão para este debate". A única que referiu acompanhar as mudanças na legislação foi a professora Maria, que afirmou consultar "a Lei de Diretrizes e Bases, documentos do Conselho Federal de EF e, agora, a Base Nacional Comum Curricular. Embora passíveis de interpretação, procuro compreender e discutir com os acadêmicos os temas polêmicos, emendas e as novidades relacionadas à legislação".

O não estar inteirado com a legislação e não fazer estudos nesse ou outros sentidos pode indicar que o processo formativo "já está dado", que o fazer pedagógico na $\mathrm{Fl}$ apresenta uma condição de "estar pronto". Isso é um problema, pois a pior formação é aquela que "nos convenceu que estamos de posse de todo o saber necessário, nada mais tendo que aprender" (Fensterseifer, 2009, p. 116). Acerca disso, entendemos da mesma forma que Bachelard, para o qual "continuar sendo estudante deveria ser o voto secreto de todo professor, o que nem de longe parece coincidir com nossa realidade" (apud Fensterseifer, 2009, p. 116). Em se tratando do "universo acadêmico", esse não estudar é ainda mais grave, pois a responsabilidade da formação de professores é dele. 


\section{CONSIDERAÇÕES TRANSITÓRIAS}

Os dados indicam que os professores atuantes na $\mathrm{FI}$ demonstram heterogeneidade de compreensões sobre a responsabilidade da EFE. Tais concepções, em grande medida, carecem de uma fundamentação teórica sistematizada, revelam um caráter fragmentário. Ao não desenvolver um processo formativo pautado por debates e estudos teóricos encorpados, acaba-se por reproduzir e influenciar os acadêmicos nessa mesma perspectiva, aos quais não é dada a oportunidade de perceber a EFE como uma disciplina que tem contribuições específicas a dar para a educação escolar.

Por um lado, entendemos que a diversidade de compreensões acerca de algo pode ser benéfica, pois permite estabelecer debates enriquecedores, os quais muitas vezes possibilitam avançar na construção de sentidos comuns. Por outro, quando as concepções carecem de sustentação teórica, podem ser consideradas como problemas, já que, em grande medida, apoiam-se na mídia e no senso comum (modismos), algumas vezes até desconhecem-se os marcos legais (os quais podem ser politicamente tensionados, mas não ignorados).

Outro dado que merece destaque é o fato do superficial conhecimento, por parte dos professores, acerca do projeto pedagógico do próprio curso em que atuam, ou seja, além de não haver um fio condutor comum para o processo formativo (devido à heterogeneidade compreensiva sobre a responsabilidade da EFE), é possível que os professores não consigam estabelecer uma visão do todo do processo formativo, o que, na maioria das vezes, conduz a ações pedagógicas dissociadas, fragmentadas e superficiais.

Não temos pretensão de colocar sob responsabilidade exclusiva da $\mathrm{Fl}$ a tarefa de resolver os problemas apresentados no texto. No entanto, por se tratar de uma questão básica para a intervenção pedagógica escolar, entendemos que o processo formativo poderia e deveria contribuir de forma mais efetiva para a compreensão da temática. Mesmo sabendo que essa pode ser apenas uma "aposta", se tivéssemos que optar nesse momento, provavelmente, cientes dos limites e das potencialidades que o processo formativo inicial apresenta, apostaríamos todas as nossas fichas nele. Afinal, é no tempo e espaço destinado à $\mathrm{Fl}$ que novos professores de EF são habilitados para exercer a docência.

Ao finalizar o percurso deste texto e imbricados em continuar a pensar acerca da temática, perguntamos: querem, os professores que atuam na $\mathrm{Fl}$, iniciar a escrita de uma nova história? Instituir novos sentidos?
Configurar uma nova cultura para a EFE? Ao mesmo tempo em que entendemos que a resposta deva ser formulada por professores e acadêmicos em cada contexto, acreditamos que a pior formação parece ser aquela que nem ao mesmo se coloca essa questão, nos deixa entregues a um subjetivismo impotente frente aos grandes desafios da EFE.

\section{FINANCIAMENTO}

Programa de Suporte à Pós-Graduação de Instituições Comunitárias (Prosuc)/Coordenação de Aperfeiçoamento de Pessoal de Nível Superior (Capes) (taxa).

\section{CONFLITOS DE INTERESSE}

Os autores declaram não haver conflitos de interesse.

\section{REFERÊNCIAS}

Bardin L. Análise de conteúdo. São Paulo: Edi,cões 70; 2011, Edi, cão revista e ampliada.

Bracht V, Caparroz FE, Della Fonte SS, Frade JC, Paiva F, Pires R. Pesquisa em a,cão: educa,cão física na escola. $3^{a}$ ljuí: Unijuí; 2014.

Bracht V, Faria BA, Machado TS, Almeida FQ, Gomes IM, Almeida UR. Desinvestimento pedagógico na educa,cão física escolar: o caso do professor José. In: Bracht V, Almeida UR, Wenetz I, editors. A educa, cão física escolar na América do Sul: entre a inova,cão e o abandono/desinvestimento pedagógico. Curitiba: CRV; 2018a. p. 51-66.

Bracht V, Faria BA, Machado TS, Almeida FQ, Gomes IM, Almeida UR. Práticas pedagógicas inovadoras na educa,cão física escolar: os casos das professoras Maria e Gabriela. In: Bracht V, Almeida UR, Wenetz I, editors. A educa,cão física escolar na América do Sul: entre a inova,cão e o abandono/ desinvestimento pedagógico. Curitiba: CRV; 2018b. p. 67-84.

Brandão CR. A pergunta a várias mãos: a experiência da pesquisa no trabalho do educador. São Paulo: Cortez; 2003.

Desgagné S. O conceito de pesquisa colaborativa: a ideia de uma aproxima,cão entre pesquisadores universitários e professores práticos. Revista Educa,cão em Questão 2007;29(15):07-35.

Fensterseifer PE. Forma, cão em educa,cão física: para sair da meno- ridade. In: Krug HN, Pereira FM, Afonso MR, editors. Educa, cão física: forma,cão e prática pedagógica. Pelotas: UFPEL; 2009. p. 103-19.

Fensterseifer PE. Forma, cão de professores de educa,cão física: uma perspectiva republicana. In: Tomazetti EM, Lopes ARLV, editors. PIBID-UFSM: experiências e aprendizagens. São Leopoldo: Oikos; 2013. p. 47-60.

González FJ, Fensterseifer PE. Educa, cão física e cultura escolar: critérios para identifica, cão do abandono do trabalho docente. Congreso de Educación Física: repensando la Educación Física 2006, Córdoba: Ipef, 2006.

González FJ, Fensterseifer PE. Entre o "não mais" e o "ainda não": pensando saídas do "não lugar" da EF escolar I. Cadernos de Forma, cão RBCE 2009a;1(1):9-24. 
González FJ, Fensterseifer PE. Desconstrucción, construcción y reconstrucción de la educación física: desafios para la formación inicial. Revista de Didáticas Específicas 2009b;1: 191-203.

González FJ, Fensterseifer PE. Entre o "não mais" e o "ainda não": pensando saídas do "não lugar" da EF escolar II. Cadernos de Forma, cão RBCE 2010;1(2):10-21.

González FJ, Fraga AB. Afazeres da educa,cão física na escola: pla- nejar, ensinar, partilhar. Erechim: Edelbra; 2012.

Machado TS, Bracht V, Faria BA, Moraes C, Almeida U, Almeida FQ. As práticas de desinvestimento pedagó- gico na educa,cão física escolar. Movimento 2010;16(2): 129-47.
Molina RMK, Molina Neto V. Pesquisar com narrativas docentes. In: Molina Neto V, Triviños ANS, editors. A pesquisa qualitativa na educa,cão física: alternativas metodológicas. $3^{a}$ ed Porto Alegre: Sulina; 2010. p. 165-76.

Rocha JCS, Nascimento JV. (Re) investimento na integralidade da forma,cão do licenciado em educa,cão física. Rev Bras Ciên Esporte 2017;39(1):56-62.

Silva AC, Lüdorf SMA, Silva FAG, Palma A. A visão de corpo na concep,cão de graduandos em educa, cão física: fragmentada ou integrada? Revista Movimento 2009;15(3):109-26. 